\title{
COMPARISON RESEARCH OF ELECTRIC VEHICLES EQUIPPED WITH FIXED RATIO GEARBOX AND TWO-SPEED GEARBOX
}

\author{
Yulong Yin, Xiaofeng Yin*, Wei Luo, Hua Sun \\ Institution of Automotive Engineering, Xihua University, Chengdu, China
}

\begin{abstract}
Parameters of powertrain system directly affect the dynamic performance and economy of electric vehicles $(E V s)$. In order to further explore the impact of the structure of powertrain system on vehicle performance, the parameters of driving motor and automatic transmission are calculated based on the performance requirements of the target vehicle. Gear ratios of transmissions with fixed ratio gearbox and two-speed gearbox are optimized respectively. The EVs with two transmission schemes are simulated under three driving cycles using the optimized gear ratios. The simulation results show that both transmissions can satisfy the requirement of vehicle power performance, while the economy of EV with two-speed gearbox is better than that of $E V$ with fixed ratio gearbox.
\end{abstract}

\section{KEYWORDS}

Electric Vehicle, Parameters Matching, Powertrain, Gear Ratio, Optimization, Performance Comparison.

\section{INTRODUCTION}

As a key component of vehicle, powertrain system needs to meet the driver's intentions under various operating conditions to achieve desired speed and driving force. Currently, both fixed ratio gearbox and multi-speed transmission are used in the powertrain of electric vehicles [1]. In order to simplify the structure of drivetrain, many electric vehicles are driven by a driving motor with a fixed ratio gearbox. At the same time, researchers are trying to apply the improved automatic transmission in conventional cars to electric vehicles so as to improve power performance and economy of complete vehicle [2]. The automatic transmissions currently used in electric vehicles mainly include automated manual transmission (AMT), dual clutch transmission (DCT), and continuously variable transmission (CVT). The application of hydraulic automatic transmission (AT) in electric vehicles is less [3]. AMT has a simple structure and low manufacturing cost, and is suitable for mass production. DCT has a short gear-shifting process without power interruption and with very good power performance and ride comfort. Both AMT and DCT have been widely used in the conventional internal combustion engine vehicles and gradually applied to electric vehicles. CVT can provide superior performance for vehicles through continuously changing of the transmission ratio, but only a small quantity of CVTs is used in electric vehicles due to its relatively complex manufacturing process, high precision requirements and high costs. 
International Journal of Recent Advances in Mechanical Engineering (IJMECH) Vol.6, No.2, May 2017

The current studies on the technical solution for motor working with a fixed ratio gearbox are mainly concerned with the parameter matching and optimization of the driving system. Literature [4] put forward a driving-motor parameter optimization method based on the operating condition of NEDC, namely adjusting the rated torque and speed of the motor to improve the contact ratio between high efficiency and NEDC and thus to prolong the driving range. Literature [5] took power performance as the constraint condition. By using the interval optimization method, it worked out the significant interval between the transmission ratios of fixed gearbox and final drive, expanding the range of parameters, solving the problem of gear matching and to some extent promoting the seriation of products.

The scope of studies on a motor working with a multi-speed transmission is relatively wide. Many studies have been made on the coordination control of several conventional automatic transmissions and motors, and some transmission companies have even developed the automatic transmissions dedicated to electric vehicles [6]. Literature [7] and [8] studied the effect of twospeed automatic transmission on the maximum speed, the maximum gradeability and energy consumption of pure electric vehicles on flat and straight road surfaces. Literature [9] and [10] compared and analyzed the effects of two transmission schemes on the overall performance of vehicles in detail by means of software simulation and bench test. Literature [11], based on the dynamic analysis of the gear-shifting process, put forward a PSO-based coordinated control strategy for two-speed dry-type DCT shifting process which obtained the optimum shifting performance through controlling the motor torque output and selecting the optimal trajectory of the clutch transmission torque.

This paper mainly studies the influence of the motor with fixed ratio scheme and the motor with two-speed transmission scheme on the power and economy performance of the vehicle, and compares the performance of two schemes. In this paper, based on a target vehicle, through the driving motor and drive train parameters matching, obtains fixed ratio and two-speed transmission schemes respectively. Based on the target function of vehicle energy consumption and accelerating time of $0-100 \mathrm{~km} / \mathrm{h}$ under various conditions to accelerate the time, the vehicle performance evaluation function is constructed by normalization, and the speed ratio of the two schemes is optimized, and the performance of the two schemes is compared after optimization by simulation.

\section{PARAmeter Matching}

Based on the principle of motor parameter selection, the motor parameters need to be determined according to the traction force required for vehicle, under different operating conditions, including the power $P_{1}$ corresponding to the power requested when driving with the maximum design speed on good straight road, the power $P_{2}$ corresponding to the power the vehicle demands to drive on ramp with the maximum slope, and the power $P_{3}$ corresponding to the power requested for acceleration $[12,13] . P_{1}, P_{2}$, and $P_{3}$ Can be expressed follows.

$$
P_{1}=\frac{u_{\mathrm{amax}}}{3600 \eta_{\mathrm{T}}}\left(m g f+\frac{C_{\mathrm{D}} A u_{\mathrm{s} \max }^{2}}{21.15}\right)
$$




$$
\begin{aligned}
& P_{2}=\frac{u_{\mathrm{a}}}{3600 \eta_{\mathrm{T}}}\left(m \mathrm{~g} f \cos \alpha_{\max }+m \mathrm{~g} \sin \alpha_{\max }\right) \\
& P_{3}=\frac{1}{3600 t_{\mathrm{m}} \eta_{\mathrm{T}}}\left(\delta m \frac{u_{\mathrm{m}}{ }^{2}}{7.2}+m g f \frac{u_{\mathrm{m}}}{1.5} t_{\mathrm{m}}+\frac{C_{\mathrm{D}} A u_{\mathrm{m}}{ }^{3}}{21.15 \times 2.5} t_{\mathrm{m}}\right)
\end{aligned}
$$

Here: $\mathrm{u}_{\mathrm{amax}}$ is maximum speed; $\mathrm{m}$ is loaded mass; $\mathrm{g}$ is acceleration of gravity; $\mathrm{f}$ is rolling resistance coefficient; ${ }^{C_{D}}$ is air drag coefficient; $A$ is windward area; ${ }_{T}$ is the mechanical efficiency of the transmission system; $\mathrm{u}_{\mathrm{a}}$ is the speed of uniform climbing; ${ }^{\alpha} \max$ is maximum climbing capability. Based on the calculation of power demand, the driving motor must meet the requirements of different power, that is, the rated power and the peak power should meet the following equations.

$$
\left\{\begin{array}{c}
P_{\mathrm{e}} \geq P_{1} \\
P_{\operatorname{enax}} \geq \max \left(P_{2}, P_{3}\right)
\end{array}\right.
$$

Through the calculation, select the power of $42 / 90 \mathrm{~kW}$, the speed of $4000 / 7200 \mathrm{r} / \mathrm{min}$ motor as the driving force of the two gear transmission scheme. Select a motor which range of torque, speed ratio is relatively large for the fixed ratio scheme, which rated power and peak power are $60 \mathrm{~kW}$ and $110 \mathrm{~kW}$; the rated speed and maximum speed are $2600 \mathrm{r} / \mathrm{min}, 6100 \mathrm{r} / \mathrm{min}$ respectively as a power source. According to the parameters of the two schemes, the basic range of the gear ratio can be calculated. Its formula is as follows.

$$
\begin{gathered}
i_{\min } \leq \frac{0.377 n_{\max } r}{u_{\max }} \\
i_{\max } \geq \frac{F_{\operatorname{tmax}} r}{\eta_{\mathrm{T}} T_{\max }}
\end{gathered}
$$

Here, $i_{\max }$ is the maximum gear ratio of the transmission; $i_{\min }$ is the minimum gear ratio of the transmission; $\mathrm{n}_{\max }$ is the maximum speed of electric motor; $\mathrm{T}_{\max }$ is the maximum torque of the motor; $F_{t \max }$ is the maximum driving force of the vehicle; $r$ is tire radius. The results are calculated according to the formula and the main parameters of the selected motor, which are as follows: minimum gear ratio of automatic transmission with two-speed scheme: $\operatorname{ig}_{\min } \leq 1$; maximum gear ratio: ${ }^{\text {ig }} \max \geq 1.4$ [13]. Single gear transmission ratio is [0.726,0.875]. In order to eliminate the influence of the main reducer on the performance of the whole vehicle, the main reduction ratio of two schemes is selected as 6.18. 


\section{OPTIMIZATION OF GEAR RATIOS}

\subsection{OBJECTIVE FUNCTION OF GEAR RATIO OPTIMIZATION}

According to the characteristics of the transmission system, the optimization variables of this chapter are the gear ratio of the two transmission schemes, the model of optimization variables can be expressed as follows.

$$
X=\left[x_{1}, x_{2}, \ldots x_{z}\right]^{T}=\left[i_{z^{1}}, i_{z^{2}}, \ldots i_{z^{*}}\right]^{T}
$$

Here, $i_{\mathrm{g} 1}$ is the gear ratio of 1 st gear; $i_{\mathrm{g} 2}$ is the gear ratio of 2 nd gear; $i_{\mathrm{gs}}$ is the gear ratio of sth gear. Through the analysis of the evaluation index of the vehicle, this paper mainly considers the optimization of vehicle $0-100 \mathrm{~km} / \mathrm{h}$ acceleration time and energy consumption as the power and economy target, constructs the comprehensive performance evaluation of vehicle function as the optimization objective function[14,15] of this chapter, transforms multi-objective optimization problem into a single objective optimization problem. Expressions are as follows.

$$
\left\{\begin{array}{c}
f(x)=w_{\mathrm{d}} \mathrm{g}_{\mathrm{d}}(x)+w_{\mathrm{j}} \mathrm{g}_{\mathrm{j}}(x) \\
w_{\mathrm{d}}+w_{\mathrm{j}}=1
\end{array}\right.
$$

Where $w_{d}, w_{j}$ are respectively the weight coefficients of dynamic and economic targets. In the formulation of the optimization scheme, the different weight coefficients show the degree of trade-off between power and economy. Because the selected sub objective functions are all dimensional, the purpose of optimization can't be achieved by the method of linear weighted, so the two functions are processed without dimension. $g_{d}(x) 、 g_{j}(x)$ are respectively the function of $0-100 \mathrm{~km} / \mathrm{h}$ acceleration time and energy consumption, and the expressions are as follows.

$$
\begin{aligned}
& \mathrm{g}_{d}(x)=\frac{t(x)-t_{\min }}{t_{\max }-t_{\min }} \\
& \mathrm{g}_{\mathrm{j}}(x)=\frac{E(x)-E_{\min }}{E_{\max }-E_{\min }}
\end{aligned}
$$

In the formula, $t_{\min }, t_{\max }$ are the minimum and maximum values of $0-100 \mathrm{~km} / \mathrm{h}$ acceleration time under different gear ratio schemes, respectively. $E_{\min } 、 E_{\max }$ are respectively the minimum and maximum values of energy consumption during the different gear ratio and single cycle condition. Due to the acceleration time and working conditions of energy consumption are very small indicators, so the smaller indicators are, the better comprehensive performance of the vehicle can be. 


\subsection{FLOW CHART OF GEAR RATIO OPTIMIZATION}

Fig. 1 is the flow chart of the optimization process of fixed ratio. Because the structure of transmission system with fixed ratio scheme is simple, it can calculate the acceleration time and the condition of energy consumption simultaneously, and put all the results into the objective function to solve. The optimization process for gear ratios of two-speed transmission is shown as Fig. 2. In order to obtain the acceleration time and working conditions can be time-consuming, it is necessary to calculate the optimal power shift schedule and the best economic shift schedule respectively, corresponding to different gear ratios, and then to optimize the gear ratio for both.

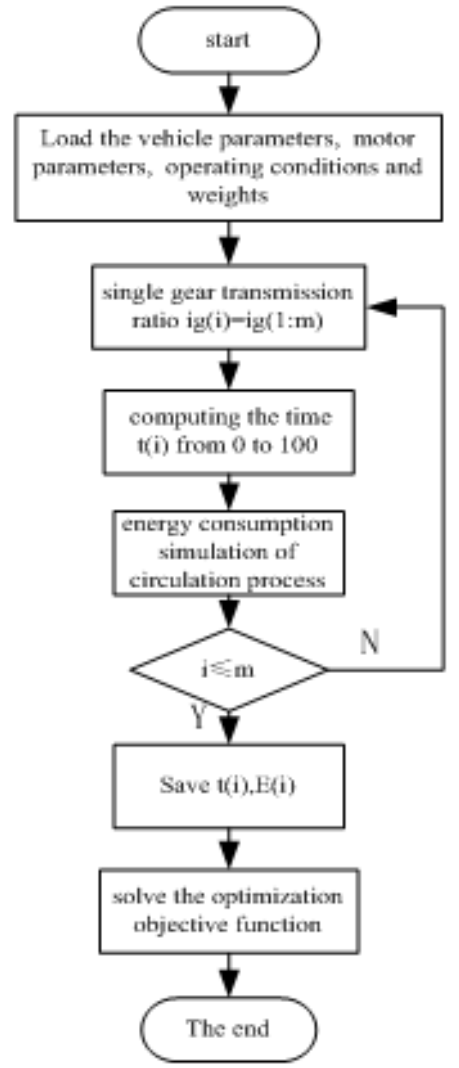

Figure 1. Optimization for fixed ratio gearbox

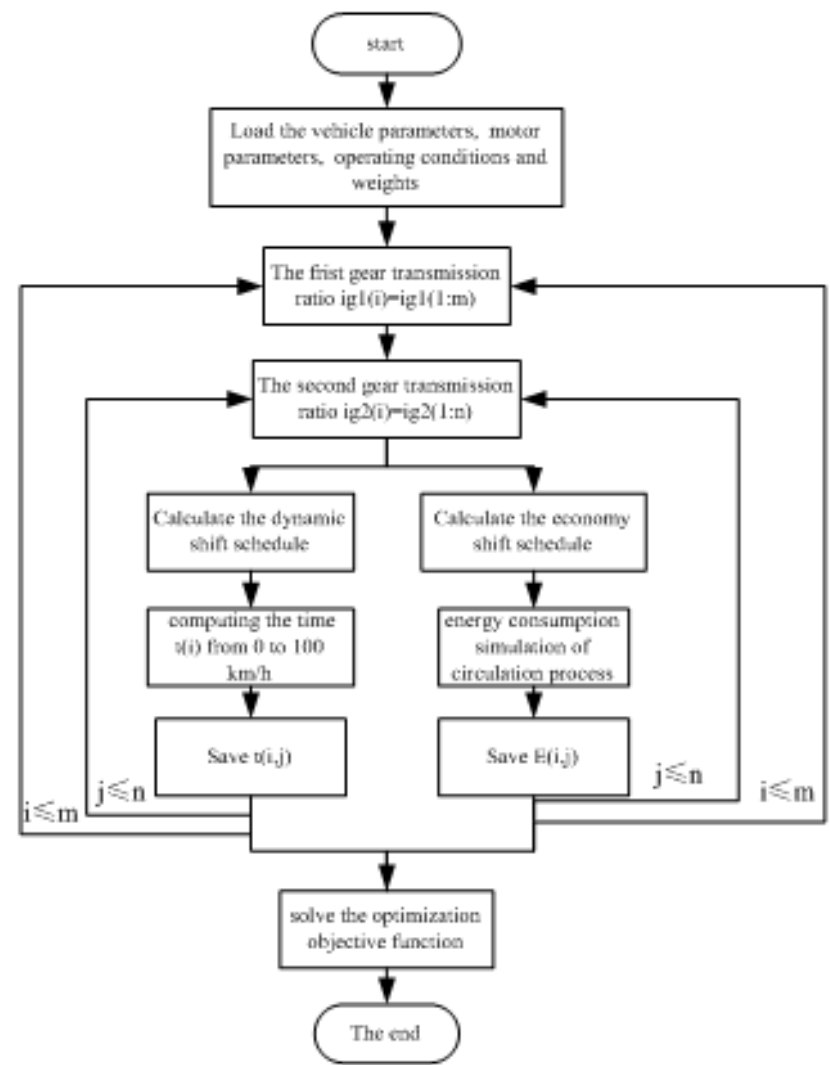

Figure 2. Optimization for 2-speed gearbox

\subsection{GEAR RATIO OPTIMIZATION RESULTS}

Because the purpose of this study is to compare the advantages and disadvantages of two transmission schemes, the weights of power performance and vehicle economy are set to $50 \%$, $50 \%$. Under the driving cycles of ECE+EUDC, UDDS and 1015[16], the paper obtained 0$100 \mathrm{~km} / \mathrm{h}$ acceleration time and energy consumption based on the three driving cycles by simulation. By using the programmed calculation procedure, the transmission ratio ranges corresponding to the above data were divided into 10 groups. After calculation, the comprehensive performance evaluation indicators for the transmission ratios of the fixed ratio and two-speed schemes were obtained. 
International Journal of Recent Advances in Mechanical Engineering (IJMECH) Vol.6, No.2, May 2017

Table 1. Comprehensive performance evaluation indicators for fixed ratio gearbox EV

\begin{tabular}{lccccc}
\hline Weights $\backslash i_{\mathrm{g}}$ & 0.726 & 0.74 & 0.76 & 0.78 & 0.80 \\
$50 \%: 50 \%$ & 0.6348 & 0.6893 & 0.8796 & 0.6688 & 0.5019 \\
\hline Weights $\backslash i_{\mathrm{g}}$ & 0.82 & 0.84 & 0.86 & 0.87 & 0.875 \\
$50 \%: 50 \%$ & 0.1871 & 0.2786 & 0.5011 & 0.3610 & 0.1547 \\
\hline
\end{tabular}

Table 2. Comprehensive performance evaluation indicators for 2-speed gearbox EV

\begin{tabular}{cccccccc}
\hline$i_{\mathrm{g} 2} \backslash i_{\mathrm{g} 1}$ & 1.4 & 1.45 & 1.5 & 1.55 & 1.6 & 1.65 & 1.7 \\
\hline 0.8235 & 0.8096 & 0.5635 & 0.6883 & 0.6716 & 0.4472 & 0.3493 & 0.5283 \\
0.85 & 0.8080 & 0.6681 & 0.8134 & 0.7673 & 0.5980 & 0.3648 & 0.6196 \\
0.9 & 0.7078 & 0.7838 & 0.7970 & 0.6372 & 0.6668 & 0.3524 & 0.4679 \\
0.95 & 0.5905 & 0.6428 & 0.5597 & 0.4620 & 0.5094 & 0.2357 & 0.3667 \\
1 & 0.6560 & 0.6113 & 0.6719 & 0.5888 & 0.4547 & 0.0392 & 0.3342 \\
\hline
\end{tabular}

In order to get the optimal transmission ratio for these two gearboxes, relationship between the transmission ratio and the comprehensive performance evaluation indicators were obtained by fitting the above results. As shown in Fig.3, the transmission ratio for the fixed ratio gearbox is selects as 0.875. Similarly, according to the fitted performance surface as shown in Fig.4, we select a combination of 1.65 and 1 as the optimal ratio of the first and the second gear for the twospeed gearbox.

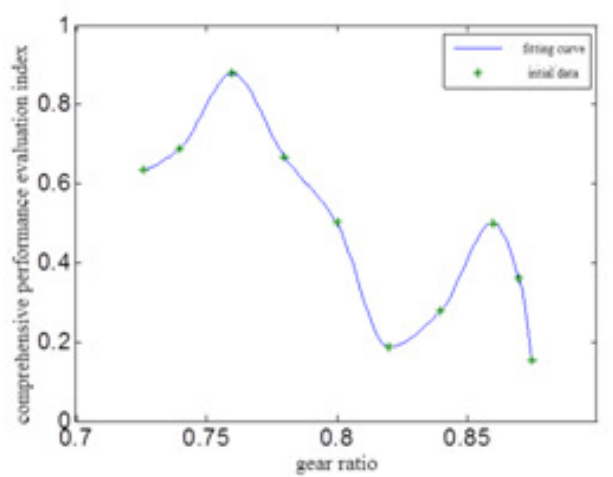

Figure 3. Performance of fixed ratio gearbox

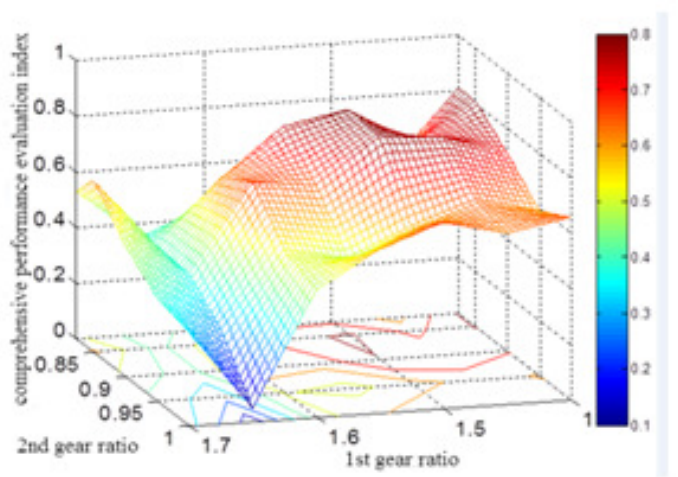

Figure 4. Performance of 2-speed gearbox

\section{SIMULATION RESULTS AND ANALYSIS}

\subsection{DYNAMIC PERFORMANCE SIMULATION}

The detailed performance indicators of the two schemes are shown in Table 3, we can know from the table that: the maximum climbing capacity of the two scheme is the same, which shows that the maximum traction force can be provided by the two transmission systems; in the case of certain parameters of the motor and transmission system, the maximum speed and the $0-100 \mathrm{~km} / \mathrm{h}$ acceleration capability of the two-speed scheme are slightly lower than that of the fixed ratio scheme, which mainly depends on the speed when electric vehicles with two-speed scheme 
International Journal of Recent Advances in Mechanical Engineering (IJMECH) Vol.6, No.2, May 2017

switch to the two gear, that is, the optimal power shift schedule has a direct impact on the two performance.

Table 3. The dynamic performance index

\begin{tabular}{cccc}
\hline Program $\backslash$ index & $\begin{array}{c}0-100 \mathrm{~km} / \mathrm{h} \\
\text { Acceleration time }(\mathrm{s})\end{array}$ & $\begin{array}{c}\text { maximum speed } \\
(\mathrm{km} / \mathrm{h})\end{array}$ & $\begin{array}{c}20 \mathrm{~km} / \mathrm{h} \\
\text { Maximum climb (\%) }\end{array}$ \\
\hline Fixed ratio & 12.1786 & 136 & 0.37 \\
transmission & 12.7160 & 135 & 0.37 \\
\hline
\end{tabular}

\subsection{PERFORMANCE COMPARISON VIA DRIVING CYCLE SIMULATION}

Table 3 is the degree that plan of the two-speed scheme is superior the fixed ratio scheme according table 2. Under the ECE+EUDC condition, the economic performance of the two-speed scheme is obviously better than that of the fixed ratio scheme, which is higher than $29.93 \%$ and $38.06 \%$, respectively; In the UDDS and 1015 driving cycles, the economic difference between the two programs is small. Fixed ratio scheme is better than the two-speed scheme of optimal power in addition to the 1015 driving cycles, the rest are slightly lower than the two-speed program. Three kinds of working conditions, the economic performance of the two-speed program generally have different degrees of advantage than the single block program.

Table 4. Energy consumption and average motor efficiency

\begin{tabular}{ccccccc}
\hline & \multicolumn{2}{c}{ ECE+EUDC } & \multicolumn{2}{c}{ UDDS } & 1015 \\
\cline { 2 - 6 } Program $\backslash$ index & $\begin{array}{c}\text { Energy } \\
\text { consumption } \\
\text { per km } \\
(\mathrm{kWh})\end{array}$ & $\begin{array}{c}\text { average } \\
\text { efficiency } \\
\text { of } \\
\text { motor/\% }\end{array}$ & $\begin{array}{c}\text { Energy } \\
\text { consumption } \\
\text { per km }(\mathrm{kWh})\end{array}$ & $\begin{array}{c}\text { average } \\
\text { efficiency } \\
\text { of motor } \\
/ \%\end{array}$ & $\begin{array}{c}\text { Energy } \\
\text { consumption } \\
\text { per km } \\
(\mathrm{kWh})\end{array}$ & $\begin{array}{c}\text { average } \\
\text { efficiency } \\
\text { of motor } \\
/ \%\end{array}$ \\
\hline $\begin{array}{c}\text { Fixed ratio } \\
\text { Optimal power }\end{array}$ & 0.2793 & 13.02 & 0.4085 & 13.61 & 0.2109 & 12.21 \\
Optimal economy & 0.1957 & 53.39 & 0.3958 & 57.40 & 0.2238 & 49.77 \\
\hline
\end{tabular}

Table 5. Comparison of energy consumption under 3 driving cycles

\begin{tabular}{|c|c|c|c|c|c|}
\hline \multirow[b]{2}{*}{ Driving cycle } & $\begin{array}{c}\text { Fixed ratio } \\
\text { scheme }\end{array}$ & \multicolumn{2}{|c|}{$\begin{array}{r}\text { Optimal power of EV } \\
\text { gearbox }\end{array}$} & \multicolumn{2}{|c|}{$\begin{array}{c}\text { Optimal-economy of EV w/ } \\
\text { 2-speed gearbox }\end{array}$} \\
\hline & $\begin{array}{c}\text { Energy } \\
\text { consumption } \\
\text { per } \mathrm{km}(\mathrm{kWh})\end{array}$ & $\begin{array}{c}\text { Energy } \\
\text { consumption } \\
\text { per } \mathrm{km}(\mathrm{kWh})\end{array}$ & $\begin{array}{l}\text { Improvement } \\
\text { amount }(\%)\end{array}$ & $\begin{array}{c}\text { Energy } \\
\text { consumption } \\
\text { per km (kWh) }\end{array}$ & $\begin{array}{l}\text { Improvement } \\
\text { amount }(\%)\end{array}$ \\
\hline $\mathrm{ECE}+\mathrm{EUDC}$ & 0.2793 & 0.1957 & 29.93 & 0.1730 & 38.06 \\
\hline UDDS & 0.4085 & 0.3958 & 3.11 & 0.3837 & 6.07 \\
\hline 1015 & 0.2109 & 0.2238 & -6.11 & 0.2037 & 3.41 \\
\hline
\end{tabular}


International Journal of Recent Advances in Mechanical Engineering (IJMECH) Vol.6, No.2, May 2017

\section{CONCLUSIONS}

The schemes corresponding to a fixed ratio gearbox and a 2-speed gearbox for an electric vehicle have been developed according to the requirement of the target vehicle, through parameter matching of the driving motor and the gearbox, respectively. And the speed ratio for both gearboxes have been optimized based on using a comprehensive performance taking into account the dynamic performance and economy as optimization objective. To compare the performance of the EV equipped with a fixed ratio gearbox and the performance of the EV equipped with a 2speed gearbox, simulation corresponding to ECE+EUDC, UDDS and 1015 driving cycles have been carried out respectively. The results show that the two-speed scheme is superior to the single-speed scheme in terms of vehicle economy while the two-speed scheme has acceptable dynamic performance compared. In order to facilitate the comparison of these two schemes, the weights corresponding to dynamic performance and economy in the objective function are set to $50 \%$, which does not take into account the relationship between the driver's intention and the weights. As one of the future work, the shift schedule considering driver's intention will be optimized in order to develop the potential of the two-speed scheme.

\section{ACKNOWLEDGEMENTS}

The work was supported in part by National Science Foundation of China(Grant No. 51375402), Science \& Technology Department of Sichuan Province (Grant Nos. 2016HH0010 and 2015TD002), and Innovation Fund for Postgraduate Students of Xihua University (Grant No. ycjj2016092).

\section{REFERENCES}

[1] Feng, Yongkai (2014), Research On Motor Transmission Integrated System Of Electric Vehicle,Dissertation, Hefei Polytechnic University, Hefei.

[2] Ji, Yi (2014), Parameter Design And Shifting Control Strategy Optimization Of Amt For Pure Electricvehicle, Dissertation, Chongqing University, Chongqing.

[3] Cheng, Qi, Feng, Yongkai, Et Al (2013), "Optimization And Simulation Of Transmission Parameter Of The Automatic Transmission In Electric Vehicle," Journal Of Mechanical Transmission, No. 6, Pp 53-57.

[4] Yu, Chaopeng, Gao, Feng, Et Al (2009), "Optimization Of Power System Parameters Matching And Dynamic Verification Of Agricultural Electric Vehicle," Journal Of Agricultural Research, Vol. 5, No.5, Pp 204-207.

[5] Wang, Bing, Lin, Xingyan, Et Al (2015), "Parameter Optimization For Pure Electric Vehicle Drive Motors Based On Driving Cycle," Chinese Journal Of Automotive Engineering, Vol. 5, No. 3, Pp $165-171$.

[6] Liu, Dongqing, Li, Chuan, Et Al (2011), “Analysis On The Transmission Of 12 Meter Pure Electric Bus," The Sixth Chinese Intelligent Transportation Conference And The Seventh International Forum On Innovation And Development Of Energy Saving And New Energy Vehicles, Beijing, China.

[7] Song, Daoyong (2013), Research On Drive And Shift Control Technology For Electric Vehicle With Two Speed Dual Clutch Transmission, Dissertation, Jilin University, Jilin. 
International Journal of Recent Advances in Mechanical Engineering (IJMECH) Vol.6, No.2, May 2017

[8] Sorniotti, Aldo, Boscolo, Marco, Turner, Andy, Et Al, "Optimization Of A Multi-Speed Electric Axle As A Function Of The Electric Motor Properties," Ieee Vehicle Power And Propulsion Conference (Vppc), Lille, France.

[9] Eberleh, B \& Hartkopf, Th (2006), "A High Speed Induction Machine With Two Speed Transmission As Drive For Electric Vehicles," International Symposium On Power Electronics, Electrical Drives, Automation And Motion, Pisa, Italy.

[10] Lu, Zhonghua (2013), Research Based On Electric Vehicle With Two-Speed Dct Controlling Technology, Dissertation, Jilin University, Jilin.

[11] Gu, Qiang, (2013), Research On Integrated Powertrain Control Technology Of Pure Electric Vehicle With Two Gears Dual Clutch Transmission, Dissertation, Jilin University, Jilin.

[12] He, Hongwen, Yu, Xiaojiang, Et Al (2006), "Study On Power Performance Of Traction Motor System For Electric Vehicle," Proceedings Of The Csee, Vo.3, No. 6, Pp 136-140 .

[13] Yu, Zhisheng (2009), Automobile Theory, Machine Industry Press, Beijing.

[14] Li, Wei (2014). Shift Schedule Optimization For Amt Of Electrical Vehicles Based On Motor Efficiency, Dissertation, Xihua University, Chengdu.

[15] Xu, Dong, Research Of Pure Electric Vehicle Dynamic Parameter Optimization Based On Ant Colony Algorithm, Dissertation, Chang 'An University, Xi'an.

[16] Ma, Youliang \& Yan, Yubing (2012), Introduction To The Electric Car, Machine Industry Press, Beijing.

\section{AUTHORS}

Yulong Yin is a postgraduate student with the Institute of Automotive Engineering, Xihua University. His research interest is optimization and control of the drive train system of vehicles equipped automatic transmission.

Xiaofeng Yin (corresponding author, email: xfyin@139.com) is a Professor with the Institute of Automotive Engineering, Xihua University. His currently research interests include vehicle drive train systems, automotive embedded control software, in-vehicle networks, and internet of vehicle. He has published over 70 papers, and owns a number of patents and software copyrights.
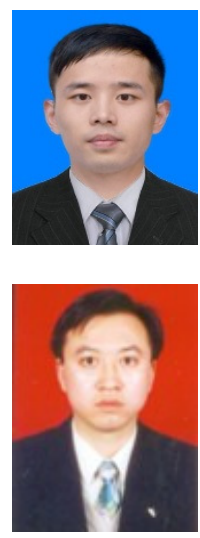